\title{
Student's Section
}

\section{Co-infection with bacterial and fungal endocarditis in neonate and successful medical treatment}

\author{
Mohammad Tahazzul*, S.N. Singh, Abhinav Sharma, Mohammad W. Khan \\ Department of Pediatrics, King George's Medical University, Lucknow, Uttar Pradesh 227107, India
}

\section{A R T I C L E I N F O}

Article history:

Received 10 October 2012

Accepted 15 December 2012

Available online 31 December 2012

Keywords:

Neonatal endocarditis

Medical treatment

Prognosis

\begin{abstract}
A B S T R A C T
Neonatal endocarditis is a rare and usually fatal disease. The diagnosis is difficult because the criteria that have suggested and used in adults are not readily applicable. We report a neonate having multiple congenital anomalies with co-infected bacterial and fungal endocarditis and successful medical treatment.

Copyright @ 2012, INDIACLEN. Publishing Services by Reed Elsevier India Pvt Ltd. All rights
\end{abstract} reserved.

\section{Background}

Neonatal endocarditis in neonates is relatively rare and is usually diagnosed on presentation symptoms such as persistent sepsis, persistent thrombocytopenia or appearance of new murmur. ${ }^{1,2}$ Neonatal endocarditis (NE) is associated with a very high mortality rate, the diagnosis is often made at postmortem examination. ${ }^{3-5}$ However, with rapidly improving technology and increasing clinical experience, the ante mortem diagnosis of NE is being made with much greater facility then in the past, and the incidence of neonatal endocarditis may be increasing. ${ }^{3}$ Here we report a neonatal having coinfected fungal and bacterial endocarditis with successful medical treatment.

\section{Case presentation}

A male baby weighing $2.5 \mathrm{~kg}$ delivered by lower segment caesarean section, was transferred to our Neonatal Intensive Care Unit (NICU) as post-operated case of trachea-oesophageal fistula with low anorectal malformation on day 3 of life. Baby was transferred with endotracheal tube in situ. The baby was put immediately on SIMV mode of mechanical ventilation with minimum settings.

On examination general condition was fair, chest bilateral clear, pansystolic murmur present, pulse palpable and good volume, capillary refill time $<3 \mathrm{~s}$.

During NICU stay, injection ceftriaxone, vancomycin was given for 28 days. On 29th day baby was transferred back to paediatric surgery for further surgical management.

In Paediatric Surgery Department, baby started having features of sepsis and transferred back to our side within 3 days. In our NICU baby was managed as a case of septicaemia. During hospital stay baby also developed right knee joint arthritis.

\section{Investigation}

During first visit to our NICU, initial investigation was done with $\mathrm{Hb} 16 \mathrm{gm} \%$, serum electrolytes within normal limit, septic screen negative and blood culture negative. The child

\footnotetext{
* Corresponding author. Tel.: +919415064135.

E-mail address: tahazzul@gmail.com (M. Tahazzul). 2213-3984/\$ - see front matter Copyright (c) 2012, INDIACLEN. Publishing Services by Reed Elsevier India Pvt Ltd. All rights reserved. http://dx.doi.org/10.1016/j.cegh.2012.12.002
} 
was ventilated for complete 6 days. Routine arterial blood gas analysis was done, with ventilatory settings managed accordingly. Two dimensional echocardiogram was done and reported atrial septal defect, ventricular septal defect and patent ductus arteriosus with no intracardiac vegetations. Chest X-ray was showing increased pulmonary vascularity with cardio-thoracic ratio of 0.6.

During 2nd visit, blood culture showed significant acinetobacter growth. Urine culture showed significant Candida albicans growth. Repeat two dimensional echocardiogram was done showing two vegetation on right ventricle wall and on pulmonary valve cusp (Fig. 1). Synovial fluid aspirate cytology and culture was done, which showed candidial growth and negative for bacterial growth. Before discharge blood, urine culture was done and was negative for bacterial as well as fungal growth.

\section{Diagnosis}

Co-infected bacterial and fungal neonatal endocarditis.

\section{Treatment}

Baby was started on fluconazole, imipenem, teicoplanin. The condition of the baby starts improving. Antifungal was given for 28 days and antibiotic for 42 days and baby was discharged from our side. Before discharge blood, urine culture was done and was negative for bacterial as well as fungal growth.

\section{Outcome}

Discharged with blood culture negative and good general condition.

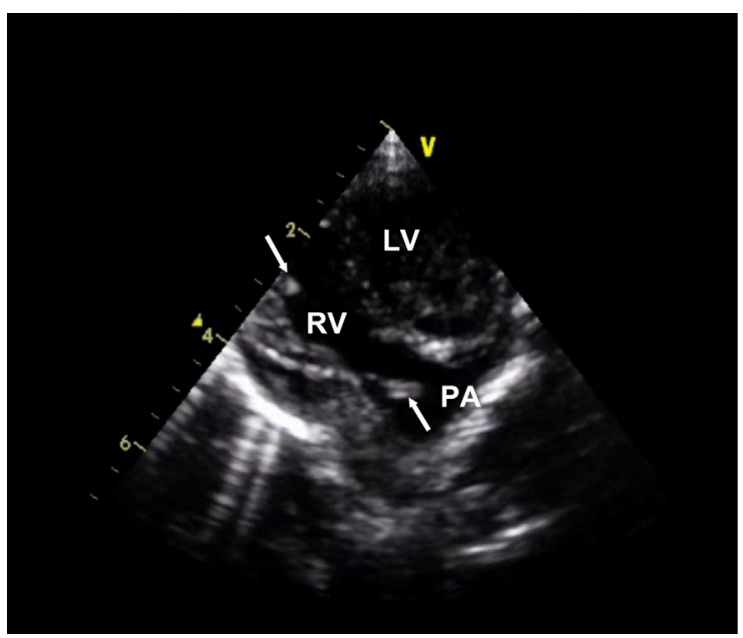

Fig. 1 - Subcoastal short axis view showing vegetation on right ventricle wall and on pulmonary valve cusp (marked by arrow).

\section{Discussion}

In our case report, we take endocardial vegetation as coinfection with fungus and bacterial because urine and synovial aspirate showed candidial growth, whereas blood culture had significant acinetobacter growth with previous echocardiogram showing no vegetation.

Fungal endocarditis is an uncommon complication of invasive candidial infection, but there is an increasing trend in the incidence of such infection over the last 15 years. ${ }^{6,7}$ Risk factors for fungal endocarditis in neonates include the following:

\section{Neonatal period}

History of cardiac surgery

Central venous catheter in place

Congenital heart disease

Broad spectrum antibacterial therapy

Pre-existing valvular lesion

Transient fungemia after bowel surgery

Any condition associated with immunocompromised state.

The clinical manifestation of NE is variable, non specific and may be indistinguishable from septicaemia or congestive heart failure. . $^{3,9}$

The right ventricle growth in our case report can be uninfected thrombus, myxoma or vegetation (Fig. 2). Echocardiogram few days before showing no growth made myxoma unlikely. It cannot be uninfected thrombus because of absence of any indwelling catheter. It is more likely to be bacterial and fungal co-infected vegetation because blood culture showed significant acinetobacter growth, urine and synovial aspirate culture showed significant candidial growth. NE caused by Candida is associated with high mortality and morbidity. ${ }^{10}$ Successful treatment often requires prolonged systemic antifungal therapy as well as surgical intervention. ${ }^{11,12}$

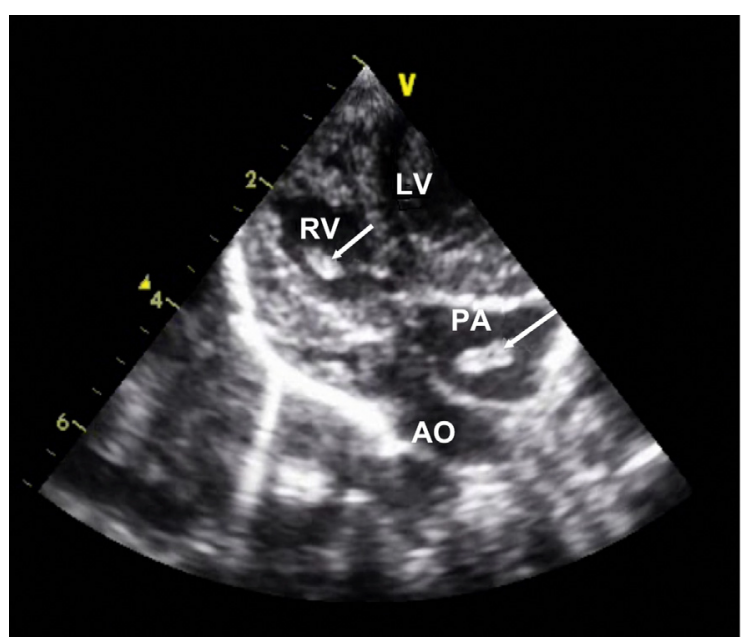

Fig. 2 - Subcoastal short axis view showing vegetation in right ventricle and pedunculated growth on pulmonary valve cusp (marked by arrow). 
Antifungal-antibiotic, frequently used in combination, is the mainstay of treatment of fungal endocarditis in neonate. ${ }^{13}$ We treated our case with antifungal-antibiotic combination and discharged.

\subsection{Learning}

1. Co-infected Candida and acinetobacter endocardial vegetation.

2. Successful fungal neonatal endocarditis treatment by medical means.

\section{Conflicts of interest}

All authors have none to declare.

\section{REFEREN C E S}

1. Manco-Johnson M, Nuss R. Neonatal thrombolytic disorders. Neo Rev. 2000;1:e201-e205.

2. Marks KA, Zucker N, Kapelushnik J, et al. Infective endocarditis successfully treated in extremely low birth weight infants with recombinant tissue plasminogen activator. Pediatrics. 2002;109:153-158.
3. Milllard DD, Shulman ST. The changing spectrum of neonatal endocarditis. Clin Perinatol. 1988;15:587-608.

4. Oelberg DG, Fisher DJ, Gross DM, et al. Endocarditis in highrisk neonates. Pediatrics. 1977;90:287-289.

5. Symchych PS, Krauss AN, Winchester P. Endocarditis following intracardiac placement of umbilical venous catheters in neonates. J Pediatr. 1977;90:287-289.

6. Koss EH, Buescher ES, Karlowicz MG. Candidemia in neonatal intensive care unit: trend during fifteen years and clinical features of 111 cases. Pediatr Infect Dis J. 1998;17:504-508.

7. Faix RG. Systemic Candida infections in infants in intensive care nurseries, high incidence of central nervous system involvement. J Pediatr. 1984;105:616-622.

8. Zenker PN, Rosenberg EM, Van Dyke RB, et al. Successful medical treatment of presumed Candida endocarditis in critically ill infants. J Pediatr. 1991;119:472-477.

9. Oelberg DG, Fisher DJ, gross DM, et al. Endocarditis in highrisk neonates. Pediatrics. 1983;71:392-397.

10. Foker JE, Bass JL, Thompson T, et al. Management of intracardiac fungal masses in premature infants. J Thorac Cardiovasc Surg. 1984;87:244-250.

11. Stoll BJ, Hansen N, Fanaroff AA, et al. Late onset sepsis in a very low birth weight neonates: the experience of NICHD Neonatal Research Network. Pediatrics. 2002;110:285-291.

12. Johnson DE, Thompson TR, Green TP, et al. Systemic candidiasis in very low birth weight infants (<1500 gm). Pediatrics. 1984;73:138-143.

13. Kaufman D, Boyle R, Hazen KC, et al. Fluconazole prophylaxis against fungal colonization and infection in preterm infants. N Engl J Med. Dec 6 2001;345(23):1660-1666. 